\title{
Treatment of whooping cough: the facts
}

\author{
J BROOMHALL AND A HERXHEIMER
}

Departments of Paediatrics, Pharmacology and Medicine, Charing Cross Hospital Medical School, London

In the welter of discussion on the hazards or benefits of pertussis vaccination scant attention has been paid to the treatment of the child who has the illness. The recent epidemic provides a strong stimulus for critical assessment of treatments in current use. Although fatality is low (14 deaths in 1982), ${ }^{12}$ whooping cough remains a prolonged and very unpleasant disease for both child and parents, with potentially serious complications, ${ }^{34}$ and standard textbooks give vague and often conflicting advice on current management. ${ }^{5-9}$.

\section{General measures}

Apart from drug treatment there has been little research into any aspect of the management of children with whooping cough. There are no clear guidelines on the indications for hospital admission, and there is no published evidence on the benefits or disadvantages of physiotherapy, mist tents, or oxygen. Even the relative merits of positioning the child sitting upright or lying prone have not been investigated. Although avoidance of factors which precipitate coughing spasms seems desirable, it is not clear what these factors are nor how much their avoidance helps. Fluid and food intake are a major problem, but the traditional teaching of feeding again immediately after a vomit remains controversial, ${ }^{7}$ and although thickening feeds has been advocated, this has never been assessed objectively.

\section{Drug treatment}

Antibiotics. ${ }^{10}$ The 1953 Medical Research Council trial $^{11}$ convincingly showed that chloramphenicol and chlortetracycline if given during the first week cleared the nasopharynx of Bordetella pertussis and shortened the course of the illness. Erythromycin ${ }^{12}$ and co-trimoxazole ${ }^{13}$ have subsequently been shown to clear the nasopharynx; ampicillin, however, had no detectable effect in vivo, although the organisms were sensitive in vitro. ${ }^{12}$ There is no evidence that any antimicrobial drug will shorten the course of the illness unless given in the first week, before the typical paroxysmal cough has developed. The sug- gestion that an antibiotic might prevent development of the disease in unvaccinated contacts ${ }^{14}$ has now been tested in two well controlled trials in the community, ${ }^{15}$ and it was found that a course of erythromycin (14 days in one trial, 10 days in the other) gave no protection.

Corticosteroids. A study in Athens ${ }^{16}$ compared 70 children given intramuscular hydrocortisone sodium succinate $(30 \mathrm{mg} / \mathrm{kg} /$ day for two days then a reducing dosage for 5-6 days) with a control group. All children had a 10 day course of erythromycin (40 $\mathrm{mg} / \mathrm{kg} /$ day). Coughing, whooping, and vomiting episodes occurred less frequently in the steroid treated groups and the illness was shorter, especially in babies under 1 year of age. The main problem with this study is that the corticosteroid group included more mild cases than the control group. The authors cautiously advocate that steroids should be used only in 'moderately severe or severe cases particularly in infants under 6 to 9 months of age'. Some short reports have suggested that oral betamethasone as the sodium phosphate $(0.075 \mathrm{mg} / \mathrm{kg} /$ day orally) ${ }^{17}$ and prednisolone $(15-20 \mathrm{mg} / \mathrm{kg} /$ day orally) ${ }^{18}$ may also be effective and need further evaluation.

Salbutamol. Badr-El-Din et al ${ }^{19}$ compared chloramphenicol alone $(100 \mathrm{mg} / \mathrm{kg} / \mathrm{day}$ IM 6 hourly) with chloramphenicol plus prednisone $(3 \mathrm{mg} / \mathrm{kg} /$ day orally, 8 hourly) and chloramphenicol plus salbutamol (four times daily $-1 \mathrm{mg}$ (under 2 years old) or 2 $\mathrm{mg}$ (over 2 years old)). In the chloramphenicol only group (18 children) no significant improvement was observed even when the drug was given early in the catarrhal stage. In the prednisone group (10 children) there was no significant improvement in the number of paroxysms, but vomiting stopped and the child's general condition improved. In the salbutamol group (13 children) there was a significant $(80 \%)$ reduction in the number of paroxysms. Although the allocation to treatments was described as random, the unequal size of the groups and apparently major differences in age and severity of the illness raise questions about the analysis and interpretation of the findings. Pavesio and 
Ponzone ${ }^{2()}$ reported an impressive early decrease in frequency of episodes of coughing and whooping in 25 children treated with salbutamol $(0.5 \mathrm{mg} / \mathrm{kg} / \mathrm{day}$ orally, in three divided doses) compared with controls. Both groups also received erythromycin (40 mg/kg/day) for 10 days. The reliability of these findings cannot be assessed from the published data. Peltola and Michelsson ${ }^{21}$ in a small uncontrolled study (four patients) also noted a rapid diminution in whooping after salbutamol but no reduction in frequency of coughing episodes.

Antitussives and antispasmodics. Since smooth muscle spasm is not causing the cough the use of antispasmodics is illogical. Mucolytics would seem a more logical choice but they do not seem to have been tried in pertussis. Thinning the mucus might facilitate drainage. Cough suppressants are generally considered ineffective against the paroxysms of whooping cough and trials have not been performed. Whether they are of any value in the later stages is also uncertain.

Sedation. The use of sedation may be the most controversial aspect of treatment. Various sedatives including diazepam, chlorpromazine, promethazine, and phenobarbitone have been recommended. They all have pharmacological properties apart from sedation that could be relevant. Some claim that the dose required to suppress coughing is often so high that the child will no longer feed, ${ }^{7}$ but others deny this. $^{22}$ It can also be argued that heavy sedation could increase the risk of lung complications. Controlled trials are needed to resolve these questions. Meanwhile one can say only that light sedation may bring some relief to the child and greater relief to the parents and physician: 'They are worth trying in a severely affected infant'.'

Therapeutic relics. Some treatments found in current publications deserve only passing mention. They include: abdominal binding-mentioned in a 1977 textbook; ${ }^{6}$ exposure to a low atmospheric pressure-claimed to help in convalescence but contraindicated in the acute stage ${ }^{23}$ hyperimmune globulin-shown not to decrease attack rate or Severity; ${ }^{24} 25$ atropine methyl nitrate (Eumydrin)symptomatic relief of whooping cough is still listed as an indication in the manufacturer's data sheet, ${ }^{26}$ but there is no published evidence of its value.

\section{Blueprint for research}

Treatment of whooping cough should aim to reduce mortality, the incidence of complications, and the severity of symptoms: it should shorten the length of the illness and prevent spread. Current treatment is largely based on the traditions and clinical experience of past generations and urgently needs scientific study.

A logical starting point for investigation would be to set up a systematic confidential enquiry into all deaths from pertussis in the recent epidemic. This should establish the risk factors upon which treatment and prevention should focus. Further investigation of the pathophysiology of whooping cough by modern techniques will allow a more logical approach to drug treatment. Good clinical trials should be set up to distinguish valuable treatments from the others.

Pathophysiological studies. The fact that widely differing groups of drugs are said to decrease the coughing spasms underlines our poor understanding of their pathophysiology. Whooping cough presents anomalous clinical, pathological, epidemiological, and immunological features. ${ }^{27}$ Although there is no bacterial invasion of any tissue and the pathological changes are not severe, profound biological changes occur, including paroxysmal coughing, lymphocytosis, changes in blood chemistry, and neurological damage. Coughing and other reactions persist for several weeks after the bacteria have cleared. Current research aims to explain these features. Protein components of $B$ pertussis have been shown to induce various biological reactions including increased susceptibility to a number of agents (histamine, serotonin, endotoxin, bradykinin, and cold); metabolic alterations (hyperglycaemia, impaired blood sugar response to adrenaline, and hyperinsulinaemia); lymphocytosis/leukocytosis; and the potentiation of the immune response to protein antigen (adjuvant activity). Pittman ${ }^{27}$ suggests that these reactions indicate the production of a protein exotoxin. Parker and Morse ${ }^{2 x}$ have shown that some of the reactions are due to alterations in the metabolism of cyclic adenosine monophosphate.

Clinical trials. Although many questions need to be answered, they are not equally important. We tentatively suggest the following order of priority. (1) Will corticosteroids and salbutamol live up to their promise? If so, which is the first choice, what are the best dosage regimens, and are there important side effects? (If salbutamol proves to be effective, theophylline may be worth investigating). (2) Does sedation help or harm? Which sedative, if any, is best? (3) Does it help to humidify the air? (4) Can mucolytics help? (5) Can physiotherapy modify the course of the illness? Which techniques are effective and in what circumstances? (6) Should children be nursed lying prone or sitting? (7) Is 
feeding again after vomiting really beneficial? Some of these questions will be difficult to answer and will require fairly complex trials both in hospital and in the community. For example the efficacy of salbuta$\mathrm{mol}$ and of prednisolone would be best assessed in multicentre studies in hospitals.

The trials will need to be carefully designed. The criteria for diagnosis must be clearly defined: it is now known that organisms other than $B$ pertussis can cause a whooping cough-like syndrome. ${ }^{29}$ Serological tests ${ }^{30}$ may therefore be desirable if the diagnosis is unproved. Treatments must be allocated at random: patients' ages, prior treatment, and time from onset of the disease should be comparable in different treatment groups. The treatments being compared must be adequate qualitatively and quantitatively (for example dosage), and be rigorously defined. Supplementary treatment should be standardised.

The most appropriate measures of outcome must be chosen. Reliable measurement of number and severity of coughing, whooping, and vomiting episodes is desirable, but difficult to achieve. Physical methods of recording paroxysms (for example sound-triggered tape recordings) deserve consideration: where possible all these assessments should be made blind. Reliable data on duration of illness demand agreed criteria for recovery, which must be developed. Points to be considered include: the absence of $B$. pertussis in the nasopharynx; return of white cell count to normal; cessation of vomiting; cessation or near cessation of cough paroxysms; resolution of complications; resumption of normal activities. Adequate long term follow up, preferably blind, will be needed to detect relapses and complications.

We believe that trials should be set up along the lines proposed as a matter of urgency. They should be centrally coordinated to ensure they are of good quality and comparable: in some cases multicentre trials will be needed. The British Paediatric Association or the Medical Research Council, or both could take charge of the coordination. Since whooping cough occurs in all countries there will also be ample opportunities for international cooperation in research on the disease.

We thank our colleagues, especially Dr David Wright, for valuable comments.

\footnotetext{
References

${ }^{1}$ Office of Population Censuses \& Surveys. Returns: 1982.

${ }^{2}$ DHSS. Review of the evidence on whooping cough vaccination by the joint committee on vaccination and immunisation. London: HMSO, 1977.

${ }^{3}$ Robinson DA, Mandal BK, Ironside AG, Dunbar EM.
}

Whooping cough - a study of severity in hospital cases. Arch Dis Child 1981;56:687-91.

${ }^{4}$ Miller CL, Fletcher WB. Severity of notified whooping cough. Br Med J 1976;i:117-9.

${ }^{5}$ Brimblecombe F, Barltrop D. Children in health and disease. 10th ed. London: Balliere Tindall, 1978.

${ }^{6}$ Silver HK, Kempe CH, Bruyn HB. Handbook of pediatrics. 12th ed. Los Altos: Lange Medical Publications, 1977.

${ }^{7}$ Christie AB. Infectious diseases, epidemiology and clinical practice. 3rd ed. Edinburgh: Churchill Livingstone, 1980.

8 Jolly H. Diseases of children. 4th ed., Oxford: Blackwell Scientific Publications, 1981.

9 Milner AD. In: Black JA, ed. Paediatric emergencies. London: Butterworth \& Co, 1979.

${ }^{10}$ Lambert H. Antimicrobial drugs in the treatment and prevention of pertussis. J Antimicrob Chemother 1979;5:329-36.

11 Medical Research Council Report. Treatment of whooping cough with antibiotics. Lancet 1953;i:1109-12.

12 Bass JW, Klenk EL, Koteimer JB et al. Antimicrobial treatment of pertussis. J Pediatr 1969:75:768-81.

13 Adcock KJ, Reddy S, Okubadejo OA, Montefiore D. Trimethoprim/sulphamethoxazole in pertussis: comparison with tetracycline. Arch Dis Child 1972;47:311-3.

14 Arneil GC, McAllister TA. Whooping cough in infants: antimicrobial prophylaxis? (letter). Lancet 1977;ii:33-4.

15 Grob PR. Spencely M. Lambert HP. Prophylactic erythromycin for whooping-cough contacts (letters). Lancet 1981;i:772-3.

${ }^{16}$ Zoumboulakis D, Anagnostakis D, Albanis V, Matsaniotis N. Steroids in treatment of pertussis. A controlled clinical trial. Arch Dis Child 1973;48:51-4.

${ }^{17}$ Chandra H, Rao CS, Karan S, Mathur YC. Evaluation of betamethasone and isoniazid along with chloramphenicol in the management of whooping cough. Indian J Pediatr 1972:9:70-4.

${ }^{18}$ Barrie H. Treatment of whooping cough (letter). Lancet 1982;ii:830-1.

19 Badr-El-Din MK, Aref GH, Kassem AS, et al. A betaadrenergic stimulant, salbutamol, in the treatment of pertussis. J Trop Med Hyg 1976;79:218-9.

${ }^{20}$ Pavesio D. Ponzone A. Salbutamol and pertussis (letter). Lancet 1977;i:150-1.

${ }^{21}$ Peltola H, Michelsson K. Efficacy of salbutamol in treatment of infant pertussis demonstrated by sound spectrum analysis. Lancet 1982;i:310-2.

22 David JA. Treatment of whooping cough (letter). $\mathrm{Br}$ Med J 1976;i:219.

${ }^{23}$ Banks HS. Decompression treatment of whooping cough; clinical survey of 903 cases. Br Med J 1955;i:1052-5.

${ }^{24}$ Morris D, McDonald JC. Failure of hyperimmune gammaglobulin to prevent whooping cough. Arch Dis Child 1957;32:236-9.

${ }^{25}$ Balagtas RC, Nelson KE, Levin S, Gotoff SP. Treatment of pertussis with pertussis immune globulin. J Pediatr 1971;79: 203-8.

26 ABPI Data Sheet Compendium 1983-84. London: Datapharm Publications, 1983:1419.

27 Pittman M. Pertussis toxin: the cause of the harmful effects and prolonged immunity of whooping cough. A hypothesis. Rev Infect Dis 1979;1:401-12.

${ }^{28}$ Parker CW, Morse SI. The effect of Bordetella pertussis on lymphocyte cyclic AMP metabolism. J Exp Med 1973;137: 1078-90.

${ }^{29}$ Linnemann CC. Bordetella. In: Weatherall DJ, Ledingham JGG, Warrell DA, eds. Oxford textbook of medicine. Oxford: University Press, 1983;5.203-5.

${ }^{30}$ Macaulay M. The serological diagnosis of whooping cough. J Hyg 1979;83:95-102.

Correspondence to $\mathrm{Dr}$ A Herxheimer, Department of Pharmacology, Charing Cross Hospital Medical School, London W6 8RF. 